\title{
When will pulmonary function recover after rib fracture?
}

\author{
Eun Gu Hwang', Yunjung Lee ${ }^{2 * *}$ \\ 'Department of Thoracic and Cardiovascular Surgery, Myongji Hospital, College of Medicine, Hanyang University, Goyang, Korea \\ ${ }^{2}$ Department of Computer Science and Statistics, Jeju National University, Jeju, Korea
}

Rib fracture is almost recovered with conservative management including oral medication. Pain is easily controlled with medication, but physiologic function is not readily evaluated. This study is aimed to investigate the factors influencing to recovery of pulmonary function test (PFT) and changes according to times after rib fracture. From August 2015 to January 2018, medical records of patients with rib fracture were reviewed retrospectively. Factors may influencing to recovery of PFT (age, chronic obstructive pulmonary disease, numbers of fractures, intercostal nerve block) were evaluated, and serial (initial, 1 month, 2 months) changes of parameters PFT (forced vital capacity [FVC], forced expiratory volume in $1 \mathrm{sec}\left[\mathrm{FEV}_{1}\right]$, total lung capacity [TLC], vital capacity [VC]) for 2 months were observed. Total patients were 60, and PFT was completed 38 and 27 patients after 1 month and 2 months respectively.
Mean age was 55.1 years (20-84 years) and mean numbers of fracture were 3.98 (1-11). Intercostal nerve block and rib fixation were performed in 32 cases and 2 cases respectively. Age, numbers of fracture and intercostal nerve block were not significant factors to changes of PFT. But chronic obstructive pulmonary disease was significant factor to recovery of $\mathrm{FEV}_{1}$ in 1 month. PFT was improved in $\mathrm{FVC}_{\text {, }} \mathrm{FEV}_{1}$ through 2 months, and improved in TLC, VC in 1 month. This study showed the evidence and prognosis of physiologic recovery after rib fracture. And we could tell about physiologic recovery to rib fracture patients with this study.

Keywords: Rib fracture, Recovery, Pulmonary function test

\section{INTRODUCTION}

Rib fracture is the most common form of chest injury that may result from falls, automobile accidents, or assaults. A simple chest posteroanterior and rib series is usually a sufficient diagnostic tool (Hurley et al., 2004); however, other methods like computed tomography and ultrasound sonography are occasionally used to verify the diagnosis (Hwang and Lee, 2016). The primary treatment goal for rib fracture is pain relief. This is mainly achieved with the use of oral nonsteroidal anti-inflammatory drugs; however, in some cases, opioids or more aggressive methods like intercostal nerve block (ICNB) (Hwang and Lee, 2014) and epidural or intravenous patient-controlled analgesia are used. The second goal is to prevent pulmonary complications like atelectasis and pneumonia through effective pain management. Effectively managing pain makes it easier for the patient to breathe deeply and expectorate sputum by coughing. Moreover, rib fractures can be treated via plate fixation when a severely displaced fracture causes a flail or deformed chest or when a rib fracture is accompanied by chronic pain or fracture-induced complications (Leinicke et al., 2013).

The prognosis for rib fracture patients is very good and, in most patients, oral drug administration or conservative treatment relieves pain in about 2-3 weeks and treatment can be withdrawn. Callus formation occurs about 8 weeks following the fracture as shown in the rib series taken during follow-up; however, in some cases, callus formation is delayed or, depending on the degree of displacement and whether fixation has been performed, the rib remains displaced. If the patient is of advanced age (Stawicki et al., 2004), has underlying lung disease, or has a lengthened mechanical ventilation period due to flail chest induced by multiple fractures, pulmonary complications and even death from pneumonia or acute respiratory distress syndrome can occasionally occur (Battle et al., 2012).
${ }^{\star}$ Corresponding author: Yunjung Lee (iD https://orcid.org/0000-0001-7394-1723 Department of Computer Science and Statistics, Jeju National University, 102 Jejudaehak-ro, Jeju 63243, Korea

E-mail: rheeyj@jejunu.ac.kr

Received: December 12, 2019 / Accepted: January 19, 2020
This is an Open Access article distributed under the terms of the Creative Commons Attribution Non-Commercial License (https://creativecommons.org/licenses/by-nc/4.0/) which permits unrestricted non-commercial use, distribution, and reproduction in any medium, provided the original work is properly cited. 
Aside from the anatomical changes related to rib fractures, the physiologic respiratory changes following rib fracture are also monitored in some studies to predict prognosis (Bakhos et al., 2006; Butts et al., 2017). The present study aimed to monitor how lung function changes over time during treatment through a periodic assessment of pulmonary function in rib fracture patients following injury and to analyze the factors that can affect the changes in lung function to explore the significance of lung function as a prognostic marker for rib fracture.

\section{MATERIALS AND METHODS}

We enrolled 60 patients with at least one rib fracture who visited the hospital from August 2015 to January 2018 and retrospectively analyzed their medical records. In this study, a pulmonary function test (PFT) was performed at the first visit after injury and then follow-up tests were performed at 1 month and 2 months postinjury. For the test, we measured the forced vital capacity (FVC), forced expiratory volume in $1 \mathrm{sec}\left(\mathrm{FEV}_{1}\right)$, total lung capacity (TLC), and vital capacity $(\mathrm{VC})$ and monitored the changes in the values

Table 1. Demographics of patients

\begin{tabular}{lc}
\hline Variable & Value \\
\hline Age $(y r)$ & $55.1(26-84)$ \\
Sex & \\
Male & 43 \\
Female & 17 \\
With COPD & \\
Yes & 11 \\
No & 49 \\
No. of fractures & $3.98(1-11)$ \\
Intercostal nerve block & \\
Yes & 32 \\
No & 28 \\
Rib fixation & 2 \\
\hline
\end{tabular}

Values are presented as median (range) or number.

COPD, chronic obstructive pulmonary disease.

Table 2. Results of serial pulmonary function tests (PFTs)

\begin{tabular}{lccc}
\hline Variable & 1st PFT ( $n=60)$ & 2nd PFT ( $n=38)$ & 3rd PFT ( $n=27)$ \\
\hline FVC (\%pred) & $1.06-4.92(32-104)$ & $1.15-5.11(56-115)$ & $1.56-5.23(70-113)$ \\
FEV $_{1}(\%$ pred) & $0.71-4.21(26-113)$ & $0.95-4.18(55-124)$ & $1.18-4.18(45-119)$ \\
TLC (\%pred) & $2.79-7.56(47-118)$ & $3.66-7.00(54-115)$ & $1.84-6.66(74-125)$ \\
VC (\%pred) & $1.07-4.88(41-121)$ & $1.31-5.14(62-119)$ & $2.07-5.40(68-104)$
\end{tabular}

Values are presented as range.

FVC, forced vital capacity; $\mathrm{FEV}_{1}$, forced expiratory volume in $1 \mathrm{sec}$; $\mathrm{TLC}$, total lung capacity; VC, vital capacity; \%pred, percent predicted. of each measure. We also investigated the variables that can influence lung function changes such as age, presence of chronic obstructive pulmonary disease (COPD) $\left(\mathrm{FEV}_{1} / \mathrm{FVC}<70 \%\right)$, number of fractures, and whether the patient had undergone ICNB. Statistical analysis of each variable was conducted using a paired $t$-test and chi-square test (SPSS 12.0, SPSS Inc., Chicago, IL, USA), with the $P$-value $\leq 0.05$ set as significant.

\section{RESULTS}

Of the patients with rib fractures who visited the hospital during the study period, a total of 60 patients had at least one fracture and had completed PFT at the first visit. The patients included 43 males and 17 females, aged 20-84 years (average age, 55.1 years) with 1-11 fractures (average, 3.98 fractures). Rib fixation was performed in two cases and ICNB performed in 32 cases. Eleven patients showed an $\mathrm{FEV}_{1} / \mathrm{FVC}$ ratio less than $70 \%$ in the first PFT and were suspected to have COPD (Table 1). Of the 60 patients who completed the first PFT, 38 completed the second PFT after 1 month and 27 completed the third PFT after 2 months. The results of the

Table 3. Significance ( $P$-values) of serial changes of PFT according to age, COPD, numbers of fracture, and ICNB

\begin{tabular}{|c|c|c|c|}
\hline Variable & O vs. 1 Month & 1 Month vs. 2 months & Ovs. 2 Months \\
\hline \multicolumn{4}{|l|}{ Age } \\
\hline FVC (\%pred) & 0.532 & 0.316 & 0.509 \\
\hline FEV 1 (\%pred) & 0.139 & 0.137 & 0.495 \\
\hline TLC (\%pred) & 0.313 & 0.845 & 0.308 \\
\hline VC (\%pred) & 0.091 & 0.237 & 0.330 \\
\hline \multicolumn{4}{|l|}{ COPD } \\
\hline FVC (\%pred) & 0.302 & 0.364 & 0.256 \\
\hline $\mathrm{FEV}_{1}(\%$ pred $)$ & 0.035 & 0.097 & 0.312 \\
\hline TLC (\%pred) & 0.515 & 0.751 & 0.404 \\
\hline VC (\%pred) & 0.172 & 0.054 & 0.435 \\
\hline \multicolumn{4}{|l|}{ ICNB } \\
\hline FVC (\%pred) & 0.312 & 0.410 & 0.345 \\
\hline $\mathrm{FEV}_{1}(\%$ pred) & 0.467 & 0.659 & 0.477 \\
\hline TLC (\%pred) & 0.527 & 0.331 & 0.425 \\
\hline VC (\%pred) & 0.650 & 0.336 & 0.204 \\
\hline \multicolumn{4}{|l|}{ Numbers } \\
\hline FVC (\%pred) & 0.333 & 0.567 & 0.210 \\
\hline FEV 1 (\%pred) & 0.448 & 0.37 & 0.261 \\
\hline TLC (\%pred) & 0.458 & 0.498 & 0.428 \\
\hline VC (\%pred) & 0.345 & 0.097 & 0.442 \\
\hline
\end{tabular}

$\mathrm{PFT}$, pulmonary function test; COPD, chronic obstructive pulmonary disease; ICNB, intercostal nerve block; $\mathrm{FVC}$, forced vital capacity; $\mathrm{FEV}_{1}$, forced expiratory volume in 1 sec; TLC, total lung capacity; VC, vital capacity; \%pred, percent predicted. 


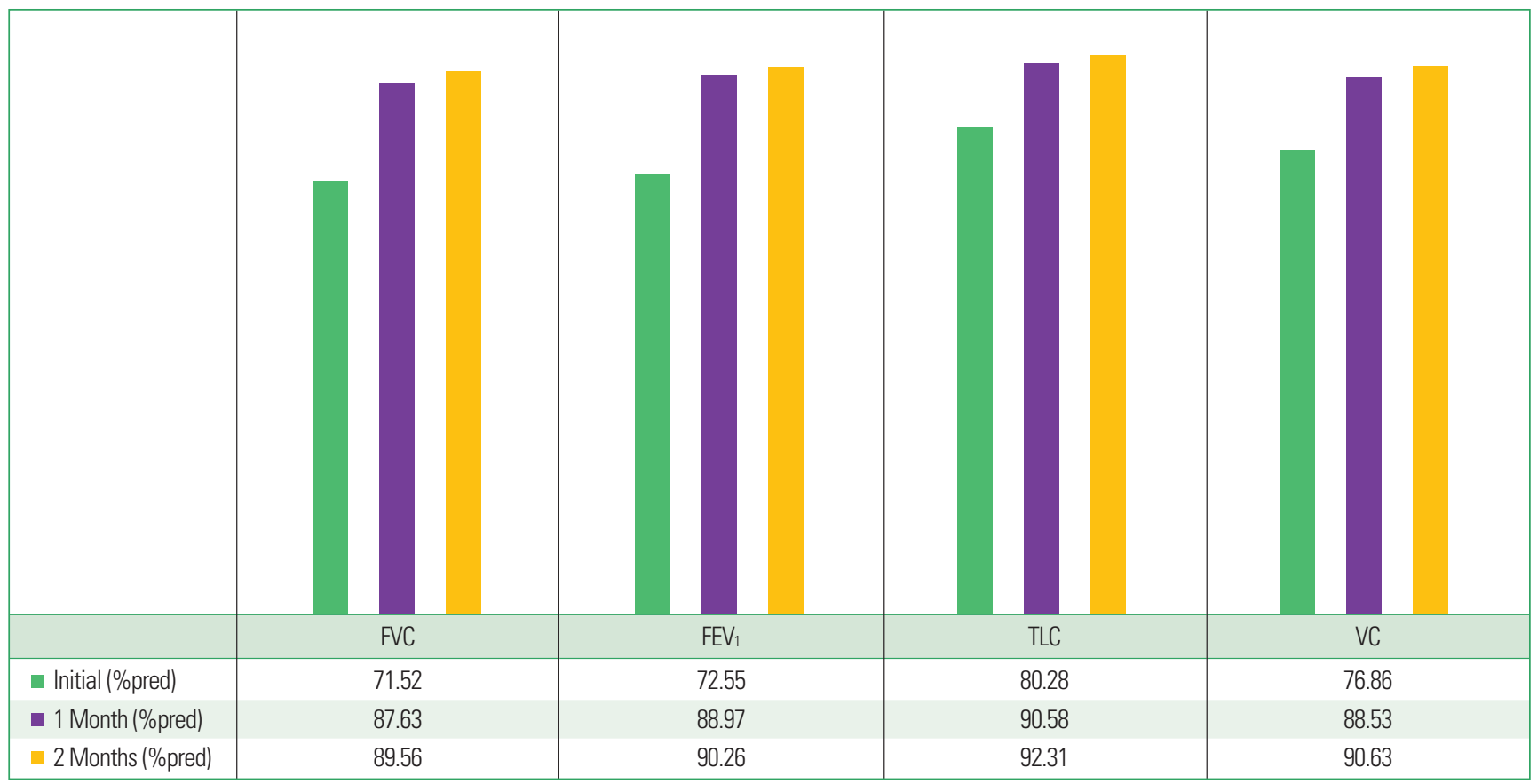

Fig. 1. Serial changes in PFT. PFT, pulmonary function test; FVC, forced vital capacity; FEV ${ }_{1}$, forced expiratory volume in 1 sec; TLC, total lung capacity; VC, vital capacity; \%pred, percent predicted.

Table 4. Significance ( $P$-values) of serial changes in PFT

\begin{tabular}{lccc}
\hline Variable & 0 vs. 1 Month & 1 Month vs. 2 Months & 0 vs. 2 Months \\
\hline FVC (\%pred) & 0.000 & 0.005 & 0.000 \\
FEV $1 \%$ pred) & 0.000 & 0.002 & 0.000 \\
TLC (\%pred) & 0.000 & 0.449 & 0.002 \\
VC (\%pred) & 0.000 & 0.216 & 0.000
\end{tabular}

PFT, pulmonary function test; FVC, forced vital capacity; FEV1, forced expiratory volume in one second; TLC, total lung capacity; VC, vital capacity; \%pred, percent predicted.

first-third PFT and mean values are provided in Table 2.

To investigate the variables that can influence PFT parameters, we explored age ( 65 years or older), the number of fractures ( 5 or more), presence of COPD, and history of ICNB. We found that these were not significant variables in the PFT parameter changes. Only the presence of COPD showed statistical significance in $\mathrm{FEV}_{1}$ recovery 1 -month postinjury $(P=0.035)$ and it was not a significant variable in the follow-up PFTs. In the second and third PFTs, VC tended to improve more in non-COPD patients $(P=0.054)$ (Table 3). Most importantly, we observed a significant change over time as the pulmonary function was periodically assessed. In the PFTs immediately following and one month after injury, statistically significant changes were observed across all parameters. In the PFTs 1 month and 2 months after injury, FVC and $\mathrm{FEV}_{1}$ con- tinued to show significant changes, whereas the measures of lung volume including TLC and VC showed no significant changes. In the end, FVC and $\mathrm{FEV}_{1}$ significantly improved up to 2-month postinjury while TLC and VC did not significantly improve beyond 1-month postinjury (Fig. 1, Table 4).

\section{DISCUSSION}

Most rib fractures healed with conservative treatment without any particular complications. Pain relief is subjective and can vary depending on individual differences and the pain management method; however, the course and degree of recovery from a rib fracture can be quantified by objective indices such as periodic radiological diagnostic testing, pulmonary function testing, and oxygen saturation testing (Battle et al., 2014). According to Bakhos et al. (2006) and Carver et al. (2015), VC is a prognostic marker in older rib fracture patients that shows pulmonary complications that may lead to the need for a long-term care facility after hospital discharge. Moreover, Battle et al. (2014) reported that the oxygen saturation level can be used as a novel prognostic marker. In the present study, we found no statistically significant improvement in lung function based on age, number of fractures, and ICNB. However, in the case of suspected COPD, it was shown to be a significant variable for $\mathrm{FEV}_{1}$ and $\mathrm{VC}$ recovery. Aside from using 
these physiological indices, a previous study attempted to measure lung function recovery by measuring lung volume via the application of a rendering technique to chest CTs (Caragounis et al., 2019).

In a study on lung function recovery based on periodic testing of pulmonary function, Caragounis et al. (2016) conducted a 1-year follow-up of patients who underwent rib fixation and reported that FVC and $\mathrm{FEV}_{1}$ improved significantly at 6- and 12-month postoperation. In a prospective study on changes in PFT between conservatively treated and surgically treated groups, Tanaka et al. (2002) reported that FVC improved continuously over 1 year in the surgically treated group. In the present study, we also confirmed a continued improvement in FVC and $\mathrm{FEV}_{1}$ over the 2 months of follow-up. However, Nickerson et al. (2016) reported that the changes in $\mathrm{FVC}$ and $\mathrm{FEV}_{1}$ monitored based on the treatment outcome of rib fixation is statistically insignificant.

The present study was based on a short-term follow-up of the pulmonary function in rib fracture patients who underwent conservative treatment. The follow-up revealed continued FVC and $\mathrm{FEV}_{1}$ improvement through 2 months postinjury and lung volume improvement (TLC and VC) through 1-month postinjury. Such findings can be explained by the fact that recovery from decreased lung compliance caused by chest pain improves over the course of treatment and is reflected in the lung capacity measures (FVC, $\mathrm{FEV}_{1}$ ) and lung volume.

Since this is a retrospective study, limitations include selection bias, small sample size, failure to verify the occurrence of pulmonary complications, and the significant shortage of rib fixation cases. Therefore, we believe that the results of this study should be verified by large-scale randomized controlled trials.

In conclusion, this study can be used as evidence for predicting the course of and explaining the recovery process of rib fractures to patients during follow-up.

\section{CONFLICT OF INTEREST}

No potential conflict of interest relevant to this article was reported.

\section{ACKNOWLEDGMENTS}

This research was supported by the 2018 scientific promotion program funded by Jeju National University.

\section{REFERENCES}

Bakhos C, O'Connor J, Kyriakides T, Abou-Nukta F, Bonadies J. Vital capacity as a predictor of outcome in elderly patients with rib fractures. J Trauma 2006;61:131-134.

Battle C, Hutchings H, Lovett S, Bouamra O, Jones S, Sen A, Gagg J, Robinson D, Hartford-Beynon J, Williams J, Evans A. Predicting outcomes after blunt chest wall trauma: development and external validation of a new prognostic model. Crit Care 2014;18:R98.

Battle CE, Hutchings H, Evans PA. Risk factors that predict mortality in patients with blunt chest wall trauma: a systematic review and metaanalysis. Injury 2012;43:8-17.

Butts CA, Brady JJ 3rd, Wilhelm S, Castor L, Sherwood A, McCall A, Patch $\mathrm{J}$, Jones $\mathrm{P}$, Cortes V, Ong AW. Do simple beside lung function tests predict morbidity after rib fractures? Am J Surg 2017;213:473-477.

Caragounis EC, Fagevik Olsén M, Granhed H, Rossi Norrlund R. CT-lung volume estimates in trauma patients undergoing stabilizing surgery for flail chest. Injury 2019;50:101-108.

Caragounis EC, Fagevik Olsén M, Pazooki D, Granhed H. Surgical treatment of multiple rib fractures and flail chest in trauma: a one-year follow-up study. World J Emerg Surg 2016;11:27.

Carver TW, Milia DJ, Somberg C, Brasel K, Paul J. Vital capacity helps predict pulmonary complications after rib fractures. J Trauma Acute Care Surg 2015;79:413-416.

Hurley ME, Keye GD, Hamilton S. Is ultrasound really helpful in the detection of rib fractures? Injury 2004;35:562-566.

Hwang EG, Lee Y. Effectiveness of intercostal nerve block for management of pain in rib fracture patients. J Exerc Rehabil 2014;10:241-244.

Hwang EG, Lee Y. Simple X-ray versus ultrasonography examination in blunt chest trauma: effective tools of accurate diagnosis and considerations for rib fractures. J Exerc Rehabil 2016;12:637-641.

Leinicke JA, Elmore L, Freeman BD, Colditz GA. Operative management of rib fractures in the setting of flail chest: a systematic review and meta-analysis. Ann Surg 2013;258:914-921.

Nickerson TP, Thiels CA, Kim BD, Zielinski MD, Jenkins DH, Schiller HJ. Outcomes of complete versus partial surgical stabilization of flail chest. World J Surg 2016;40:236-241.

Stawicki SP, Grossman MD, Hoey BA, Miller DL, Reed JF 3rd. Rib fractures in the elderly: a marker of injury severity. J Am Geriatr Soc 2004;52: 805-808.

Tanaka H, Yukioka T, Yamaguti Y, Shimizu S, Goto H, Matsuda H, Shimazaki S. Surgical stabilization of internal pneumatic stabilization? A prospective randomized study of management of severe flail chest patients. J Trauma 2002;52:727-732. 